\title{
Estimating Reductions in Ethnic Inequalities in Child Adiposity from Hypothetical Diet, Screen Time, and Sports Participation Interventions
}

\author{
Macarena Lara, ${ }^{\mathrm{a}}$ Jeremy A. Labrecque, ${ }^{\mathrm{a}}$ Frank J. van Lenthe, ${ }^{\mathrm{b}}$ and Trudy Voortman ${ }^{\mathrm{a}}$
}

\begin{abstract}
Background: Childhood obesity is a global epidemic, and its prevalence differs by ethnicity. The objective of this study was to estimate the change in ethnic inequalities in child adiposity at age 10 resulting from interventions on diet at age 8 and screen time and sports participation at age 9 .

Methods: We conducted a population-based cohort study, the Generation R Study, from 9,749 births in Rotterdam (2002-2006), of which 9,506 children remained in the analysis. We measured ethnicity, diet, screen time, and sports participation through questionnaires; we measured weight, body mass index (BMI), fat mass index, and fatfree mass index directly. We used sequential G-estimation to estimate the reduction in inequality that would result from the interventions.

Results: We observed that sociodemographic characteristics, diet, screen time, sports participation, and all adiposity measurements were more favorable in children from Western versus non-Western ethnic backgrounds: weight $=-1.2 \mathrm{~kg}(95 \%$ confidence interval $[\mathrm{CI}]$ $=-1.7,-0.8), \mathrm{BMI}=-1.0 \mathrm{~kg} / \mathrm{m}^{2}(\mathrm{CI}=-1.2,-0.9)$, and fat mass index $=-0.8 \mathrm{~kg} / \mathrm{m}^{2}(\mathrm{CI}=-0.9,-0.7)$. We estimated that extreme intervention (maximum diet score of 10 , no screen time, and $>4$ hours/ week of sports) reduced ethnic inequalities by $21 \%(\mathrm{CI}=8 \%, 35 \%)$ for weight, $9 \%(\mathrm{CI}=4 \%, 14 \%)$ for $\mathrm{BMI}$, and $9 \%(\mathrm{CI}=6 \%, 13 \%)$ for fat mass index. A diet score $\geq 5$ points, screen time $\leq 2$ hours/day, and sports participation $>2$ hours/week reduced ethnic inequalities by $17 \%(\mathrm{CI}=6 \%, 28 \%)$ for weight, $7 \%(\mathrm{CI}=3 \%, 11 \%)$ for $\mathrm{BMI}$, and $7 \%(\mathrm{CI}=4 \%, 10 \%)$ for fat mass index.

Conclusions: Our results are consistent with the hypothesis that interventions integrating diet, screen time, and sports participation have a moderate impact on reducing ethnic inequalities in child adiposity.
\end{abstract}

Keywords: Adiposity; Body mass index; Child; Diet; Ethnic inequalities; Screen Time; Sports Participation

(Epidemiology 2020;31: 736-744)

Submitted August 9, 2019; accepted May 29, 2020.

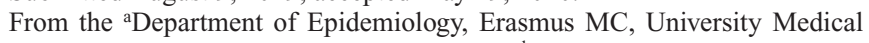
Center, Rotterdam, The Netherlands; and 'bepartment of Public Health, Erasmus MC, University Medical Center, Rotterdam, The Netherlands. The authors report no conflicts of interest.

SDC Supplemental digital content is available through direct URL citations in the HTML and PDF versions of this article (www.epidem.com).

Correspondence: Macarena Lara, Department of Epidemiology, Erasmus MC, 3000 CA Rotterdam, The Netherlands. E-mail: m.laramolina@erasmusmc.nl.

Copyright $(C 2020$ Wolters Kluwer Health, Inc. All rights reserved. ISSN: $1044-3983 / 20 / 3105-0736$

DOI: 10.1097/EDE.0000000000001221
$\mathrm{O}$ besity is a global epidemic and public health problem in both adults and children. During the last 4 decades, its worldwide prevalence has nearly tripled in adults and increased 10-fold in children and adolescents. In 2016, 13\% of adults and $7 \%$ of children and adolescents had obesity. ${ }^{1,2}$

According to the World Health Organization, obesity is a major risk factor for cardiovascular diseases, diabetes, osteoarthritis, and some cancers. ${ }^{1}$ Previous research suggests that early prevention of obesity in children may be the best approach to prevent future increases in morbidity and healthcare costs that will likely occur as children with obesity age. ${ }^{3}$

Obesity is not equally distributed throughout the population. Ethnic minorities in European countries have been found to have a higher burden of overweight and obesity both in adults and children. ${ }^{4-6}$ However, little is known about the degree to which specific factors are driving these inequalities and the pathways through which differences in body mass and body composition occur. Improving our knowledge of these mechanisms will inform where public health interventions can have the largest impact to reduce ethnic inequalities in obesity in the population from childhood onward.

The Netherlands has a long history of immigration. ${ }^{7}$ Currently, of its 17.3 million inhabitants, $24 \%$ are immigrants or the children of immigrant parents. ${ }^{8}$ The country has committed to reducing socioeconomic inequality in life expectancy by $25 \%$ by the year 2020 yet it appears that despite the implementation of various intervention programs, the country has not yet achieved this goal. ${ }^{9}$ In the period 2011-2014, life expectancy was 85 among those with the highest household income and 77 years among those with the lowest household income. ${ }^{10}$ Reducing ethnic inequalities in cardiovascular risk factors that mediate the relationship between child adiposity and mortality due to cardiovascular disease could help in achieving this commitment. ${ }^{1-14}$

The objective of this study was to estimate the change in ethnic inequalities in child adiposity at age 10 resulting from hypothetical interventions on diet at age 8 and screen time and sports participation at age 9. We used sequential G-estimation to separate the estimation of the inequality and the model for the interventions separately to avoid adjusting the inequality itself for covariates, which occurs when both models are fit together. 


\section{METHODS}

\section{Study Design}

We used data from the Generation R Study, a populationbased prospective cohort study whose purpose is to identify early environmental and genetic determinants of growth, development, and health from fetal life until young adulthood. ${ }^{15}$

The Generation R Study is set in Rotterdam, the second largest city in the Netherlands. As a port and industrial city, its economic growth has led to large-scale migration. ${ }^{16}$ In 2019, Rotterdam had 644,618 inhabitants and $29 \%$ of them born abroad. The largest immigrant communities were from Suriname, Turkey, Morocco, and the Dutch Caribbean. ${ }^{17}$

\section{Study Population}

All pregnant women living in Rotterdam and with an expected delivery date between April 2002 and January 2006 were invited to participate. At baseline, 9,778 mothers were enrolled in the study of which 9,749 had live born children. ${ }^{15}$ A flow chart for this study is presented in the Figure.

\section{Collection of Information Ethnic Background}

A participant was considered to be of non-Dutch ethnic origin if one of their parents was born abroad as reported by their parents on a questionnaire applied at baseline. If both parents were born abroad, the country of birth of the participant's mother determined the child's ethnic background. ${ }^{15} \mathrm{~A}$ dichotomous variable, 1: "Western ethnic background" and 0: "Non-Western ethnic background," was constructed according to the national classification by Statistics Netherlands. ${ }^{18}$ It was designed to reflect the social and economic position

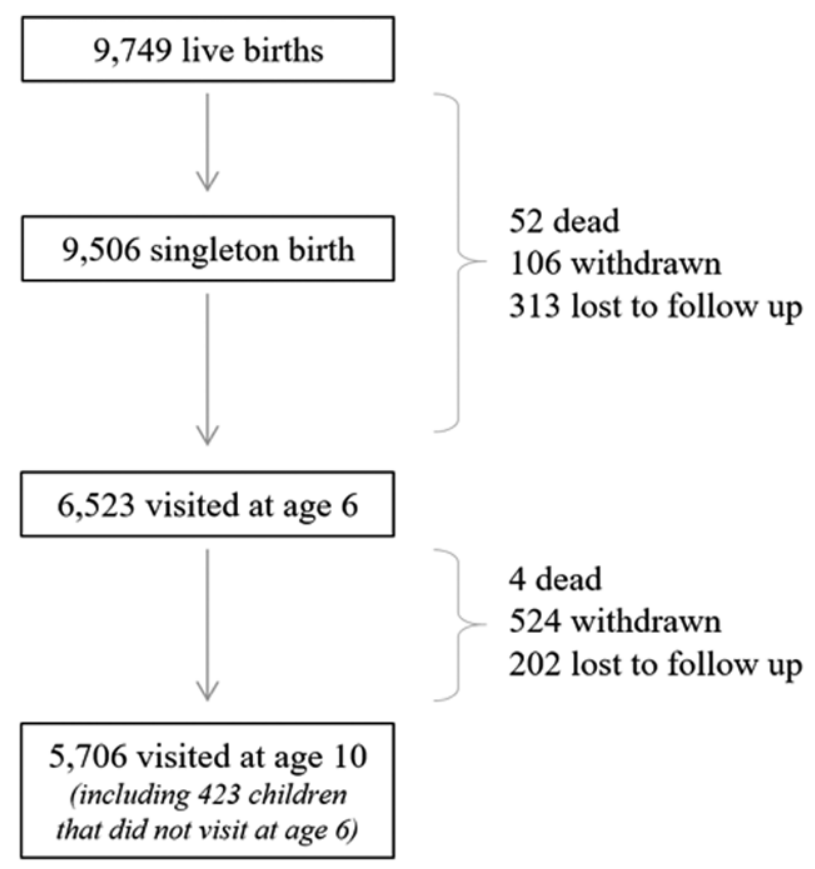

FIGURE. Flow chart of the participant included in this study. of people in Dutch society. Western ethnicity included Dutch, European, North American, Oceanian, Japanese, and Indonesian (former Dutch East Indies). Non-Western ethnicity included Turkish, African, Latin-American, and Asian (except Indonesia and Japan).

\section{Diet, Screen Time, and Sports Participation}

A semiquantitative food frequency questionnaire was completed by the parents when the child was 8 years old. Frequency and amount of food consumed by the child during the last 4 weeks was registered and then converted into $\mathrm{g}$ /day. A diet quality score was computed, by calculating the ratio of reported and recommended food intake by age group for 10 items: fruit ( $\geq 150 \mathrm{~g} / \mathrm{d})$, vegetables $(\geq 150 \mathrm{~g} / \mathrm{d})$, whole grains $(\geq 90 \mathrm{~g} / \mathrm{d})$, fish ( $\geq 60 \mathrm{~g} /$ week), legumes ( $\geq 84 \mathrm{~g} /$ week), nuts $(\geq 15 \mathrm{~g} / \mathrm{d})$, dairy $(\geq 300 \mathrm{~g} / \mathrm{d})$, oils and soft or liquid fats $(\geq 30 \mathrm{~g} / \mathrm{d})$, sugar-containing beverages $(\leq 150 \mathrm{~g} / \mathrm{d})$, and highfat and processed meat $(\leq 250 \mathrm{~g} /$ week $) .{ }^{19}$ Total score for diet quality ranged from 0 to 10 on a continuous scale, with a higher score indicating a better overall diet quality. The methodology to obtain this diet score has been published previously. $^{20}$

Screen time and sports participation were assessed by parent-reported questionnaire when the child was 9 years old. Screen time included television viewing, video/DVD use, and computer game use. Frequency and duration of these activities were asked for weekdays and weekend days separately. We combined these variables to estimate the average daily screen time. $^{21}$ Sports considered included soccer, hockey, basketball, handball, korfball, tennis, judo, karate, gymnastics, jazz ballet, etc. We did not include school sports activities such as physical education lessons and swimming lessons in this variable. Sports participation was categorized into less than 1 hour, from 1 to 2 hours, from more than 2 to 4 hours and more than 4 hours a week.

\section{Adiposity Indicators}

Child anthropometrics and body composition were measured at 6 and 10 years old by trained staff in a dedicated research center at Erasmus MC-Sophia Children's Hospital. Height was determined in standing position to the nearest millimeter without shoes with a Harpenden stadiometer (Holtain Limited, Dyfed, United Kingdom). Weight was measured using a mechanical personal scale (SECA, Almere, The Netherlands). Body mass index was calculated as body weight $(\mathrm{kg}) /$ height $(\mathrm{m})^{2}$. Body composition was measured using a dual-energy X-ray absorptiometry (DXA) scanner (iDXA; GE-Lunar, 2008, Madison, WI). Fat mass index [fat mass $(\mathrm{kg}) /$ height $(\mathrm{m})^{2}$ ] and fat-free mass index [fat-free mass $(\mathrm{kg}) /$ height $(\mathrm{m})^{2}$ ] were calculated.

This study was conducted in accordance with the guidelines proposed in the World Medical Association's Declaration of Helsinki and has been approved by the Medical Ethical Committee at Erasmus Medical Center, University Medical 
Center Rotterdam. Written informed consent was obtained from all participants' parents.

\section{Analysis}

Recent thinking on health inequalities and finding interventions to reduce them has made it clear that, although these questions resemble mediation analyses, there are important differences. ${ }^{22-24}$ For example, the degree to which a health inequality would change if an intervention was implemented is not a type of controlled direct effect because we are not interested in intervening on the group that defines the inequality, ethnicity, in this case. ${ }^{24}$ Our parameter of interest can nonetheless be expressed as a counterfactual as the change in a descriptive parameter, the inequality in an adiposity measurement at age 10, that would be observed at the same age if we intervened on a variable which potentially mediates the relationship between ethnicity and the outcome (adiposity measurement). The change in inequality with and without the hypothetical intervention could be estimated by comparing the difference between the inequality when the intervention has been implemented and the original observed inequality without the intervention.

Despite the fact that variables such as diet, physical activity, and screen time are potential mediators of the relationship between ethnicity and adiposity measurements, it is more convenient to think of this estimate as the change in a descriptive quantity expected from a specified intervention. Sequential G-estimation can be used for this purpose because it allows for covariate adjustment of the intervention model while avoiding adjustment for the estimation of the inequality. ${ }^{25}$ This method first estimates a model of the effect of the intervention on the outcome using linear regression while adjusting for potential confounders which were selected using causal graphs and the relevant literature. In this study, confounders were collected through questionnaires (ethnic background, household income, maternal education, parity, marital status, maternal age, smoking and alcohol consumption during pregnancy, maternal prepregnancy body mass index, paternal body mass index), medical records (child sex, age, birth weight, gestational age, maternal weight gain during pregnancy), and physical measurements at the research center (child adiposity measurement at age 6). This model requires three causal assumptions: exchangeability (i.e., that there is no residual confounding or bias due to selection bias between the proposed intervention and the measure of adiposity), positivity (i.e., that there is variation in the exposure conditional on confounders), and consistency (i.e., that the interventions is well defined). Consistency is likely not satisfied for screen time because we are not specifying an activity to replace screen time. However, this may be mitigated to an extent when we combine all interventions thereby replacing some screen time with sports participation. Using this model for the intervention, it is possible to estimate the value of the outcome if the intervention was set to different levels. Using this value of the outcome where the intervention is set to a specific level, the inequality had the intervention been implemented can be estimated. The difference between the inequality with and without the intervention is the change in ethnic inequality that would result from the intervention in question. Dividing this change by the inequality without the intervention gives the percent change in inequality. The results were expressed through the percent change in ethnic inequality and $95 \%$ confidence intervals (CIs). The code for the analysis, and which is designed to be easily repurposed by the user, can be found in the eAppendix; http://links.lww.com/EDE/B679.

We set diet score, screen time, and sports participation to the specific levels in each hypothetical intervention (Table 1). For the hypothetical extreme interventions, we used the maximum possible value and we decided on hypothetical cutoffs for the moderate interventions based on a combination of guidelines, categories available in our questionnaires and the distribution of the data.

For example, for the intervention setting diet score to five or greater, all children whose observed diet score was less than five were set to be equal to five. Equivalently, for the intervention where screen time is set to less than or equal to 2 hours/day, all children whose observed screen time was greater than 2 were set to be equal to 2 . For the intervention setting sports participation to more than 4 hours a week, all children were set to the 4 or more hours a week category. An interaction term between ethnicity and each intervention was considered and retained if it had an important effect on the change in inequality. We also checked for interactions between the proposed interventions and sex.

We excluded twin births from the analysis $(n=243)$ to avoid data clustering and due to birth weight and developmental differences. We quantified losses to follow-up and contrasted the characteristics of the group that remained in

TABLE 1. Hypothetical Interventions Used

\section{Hypothetical Interventions}

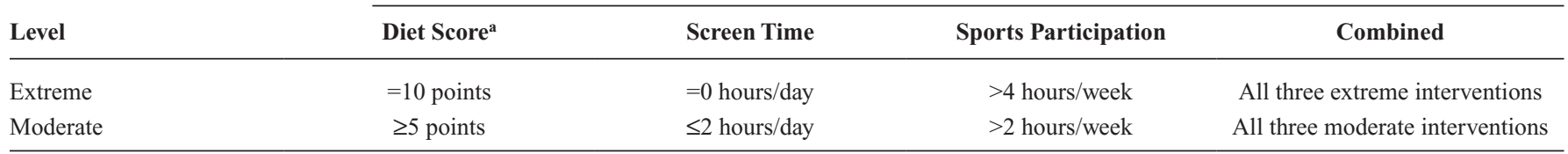

${ }^{\mathrm{a}} \mathrm{A}$ diet score of 10 indicates a better overall diet quality. 
the study with the group that was lost to verify whether the losses to follow-up were related to ethnic group, intervention, or outcome, which could introduce a selection bias. ${ }^{26}$ To avoid selection bias associated with missing data, we performed multiple imputation by chained equations in $\mathrm{R}$ (15 imputed data sets, 1,000 iterations) using the fully conditional specification method. ${ }^{27}$ More information can be found in eTable 1; http://links.lww.com/EDE/B679. Statistical analyses were performed using $\mathrm{R}$ version 3.6.1.

\section{RESULTS}

Sociodemographic characteristics at baseline were different between followed children and those lost to follow-up. For example, children who were lost to follow-up had lower birth weight and came from families with a non-Western ethnic background that had lower income and education (Table 2).

General characteristics of the sample after multiple imputation are shown in Table $3(\mathrm{n}=9,506)$. Children from a Western ethnic background had a birth weight $130.6 \mathrm{~g}$ higher than children from a non-Western ethnic background. Mothers from a Western ethnic background were 2.6 years older and had a prepregnancy body mass index $1.6 \mathrm{~kg} / \mathrm{m}^{2}$ lower than mothers from a non-Western ethnic background, 12\% more were nulliparous, and $15 \%$ more were married or living with a couple. Fathers from a Western ethnic background had a body mass index $0.5 \mathrm{~kg} / \mathrm{m}^{2}$ lower than fathers from a non-Western ethnic background. Both household income and maternal education were higher in families from Western than from nonWestern ethnic backgrounds.

Table 4 shows that diet score, screen time, and sports participation were healthier in children from Western compared with non-Western ethnic backgrounds. All the adiposity measurements were lower in children from Western compared with
non-Western ethnic backgrounds at both 6 and 10 years old, and the difference was larger at age 10 . The observed ethnic inequality at age 10 was $-1.2 \mathrm{~kg}(95 \% \mathrm{CI}=-1.7,-0.8)$ for weight, $-1.1 \mathrm{~kg} / \mathrm{m}^{2}(\mathrm{CI}=-1.2,-0.9)$ for body mass index (BMI), and $-0.8 \mathrm{~kg} / \mathrm{m}^{2}(\mathrm{CI}=-0.9,-0.7)$ for fat mass index (Table 5).

Table 5 also shows how different hypothetical lifestyle interventions would reduce ethnic inequalities in child adiposity at 10 years old. The interactions between sex and each intervention were all above $P>0.2$ except for the screen time model with fat-free mass index as the outcome $(P=0.18)$. Based on these results, we chose not to stratify by sex. Reducing screen time was the specific intervention that mostly decreased ethnic inequalities in each measure of adiposity, followed by sports participation which also reduced inequalities but less so. Interventions related to diet score improvement did not appear to reduce ethnic inequalities in child adiposity. There was little difference in the amount of ethnic inequality reduced by the extreme and moderate interventions. The inequality in weight was the most reduced by the proposed interventions, followed by body mass index and fat mass index. There was little to no change in fat-free mass index.

Generally, combined diet, screen time, and sports participation interventions showed the largest reductions in ethnic inequalities in child adiposity. The most extreme intervention that would maximize the diet score, reduce screen time to 0 hours a day, and increase sports participation to over 4 hours a week showed reductions in ethnic inequalities by $21 \%(\mathrm{CI}=8 \%, 35 \%)$ for weight, $9 \%(\mathrm{CI}=4 \%, 14 \%)$ for body mass index, and $9 \%(\mathrm{CI}=6 \%, 13 \%)$ for fat mass index. Having a diet score of five points or higher, no more than 2 hours a day of screen time, and more than 2 hours a week of sports participation combined also reduced ethnic inequalities by $17 \%(\mathrm{CI}=6 \%, 28 \%)$ for weight, $7 \%(\mathrm{CI}=3 \%, 11 \%)$

TABLE 2. Sociodemographic Characteristics of the Participants at Baseline, by Follow-up Status at Age 10

\begin{tabular}{|c|c|c|c|c|}
\hline \multirow[b]{2}{*}{ Characteristics } & \multicolumn{2}{|c|}{ Followed at Age 10} & \multicolumn{2}{|c|}{ Lost to Follow-up } \\
\hline & $\mathbf{n}$ & Mean (SD) & $\mathbf{n}$ & Mean (SD) \\
\hline Birth weight $(\mathrm{g})$ & 5,696 & $3,433.1(553.6)$ & 3,727 & $3,373.5(577.0)$ \\
\hline Gestational age (weeks) & 5,669 & $39.9(1.8)$ & 3,749 & $39.7(2.1)$ \\
\hline Maternal age (y) & 5,705 & $30.9(5.0)$ & 3,799 & $28.3(5.6)$ \\
\hline Maternal weight gain during pregnancy (g/week) & 4,289 & $189.5(238.3)$ & 2,644 & $193.8(275.5)$ \\
\hline Maternal prepregnancy body mass index $\left(\mathrm{kg} / \mathrm{m}^{2}\right)$ & 4,298 & $23.5(4.1)$ & 2,655 & $23.9(4.7)$ \\
\hline \multirow[t]{2}{*}{ Paternal body mass index $\left(\mathrm{kg} / \mathrm{m}^{2}\right)$} & 4,031 & $25.3(3.4)$ & 2,147 & $25.4(3.8)$ \\
\hline & \multicolumn{2}{|c|}{$\mathrm{n}(\%)$} & \multicolumn{2}{|c|}{$\mathrm{n}(\%$} \\
\hline Child sex (male) & \multicolumn{2}{|c|}{$5,705(50)$} & \multicolumn{2}{|c|}{$3,798(52)$} \\
\hline Child ethnicity (Western ethnic background) & \multicolumn{2}{|c|}{$5,561(69)$} & \multicolumn{2}{|c|}{$3,306(53)$} \\
\hline Household income (>1,600€ per month) & \multicolumn{2}{|c|}{$4,418(77)$} & \multicolumn{2}{|c|}{$2,192(55)$} \\
\hline Maternal education (University) & \multicolumn{2}{|c|}{$5,237(50)$} & \multicolumn{2}{|c|}{$3,095(30)$} \\
\hline Marital status (married/living together) & \multicolumn{2}{|c|}{$5,234(89)$} & \multicolumn{2}{|c|}{$3,109(80)$} \\
\hline Parity (nulliparous) & \multicolumn{2}{|c|}{$5,521(57)$} & \multicolumn{2}{|c|}{$3,625(52)$} \\
\hline Smoking during pregnancy (yes) & \multicolumn{2}{|c|}{$4,979(24)$} & \multicolumn{2}{|c|}{$3,045(32)$} \\
\hline Alcohol consumption during pregnancy (yes) & \multicolumn{2}{|c|}{$4,570(57)$} & \multicolumn{2}{|c|}{$2,864(40)$} \\
\hline
\end{tabular}


TABLE 3. Sociodemographic Characteristics at Baseline by Ethnicity After Multiple Imputation

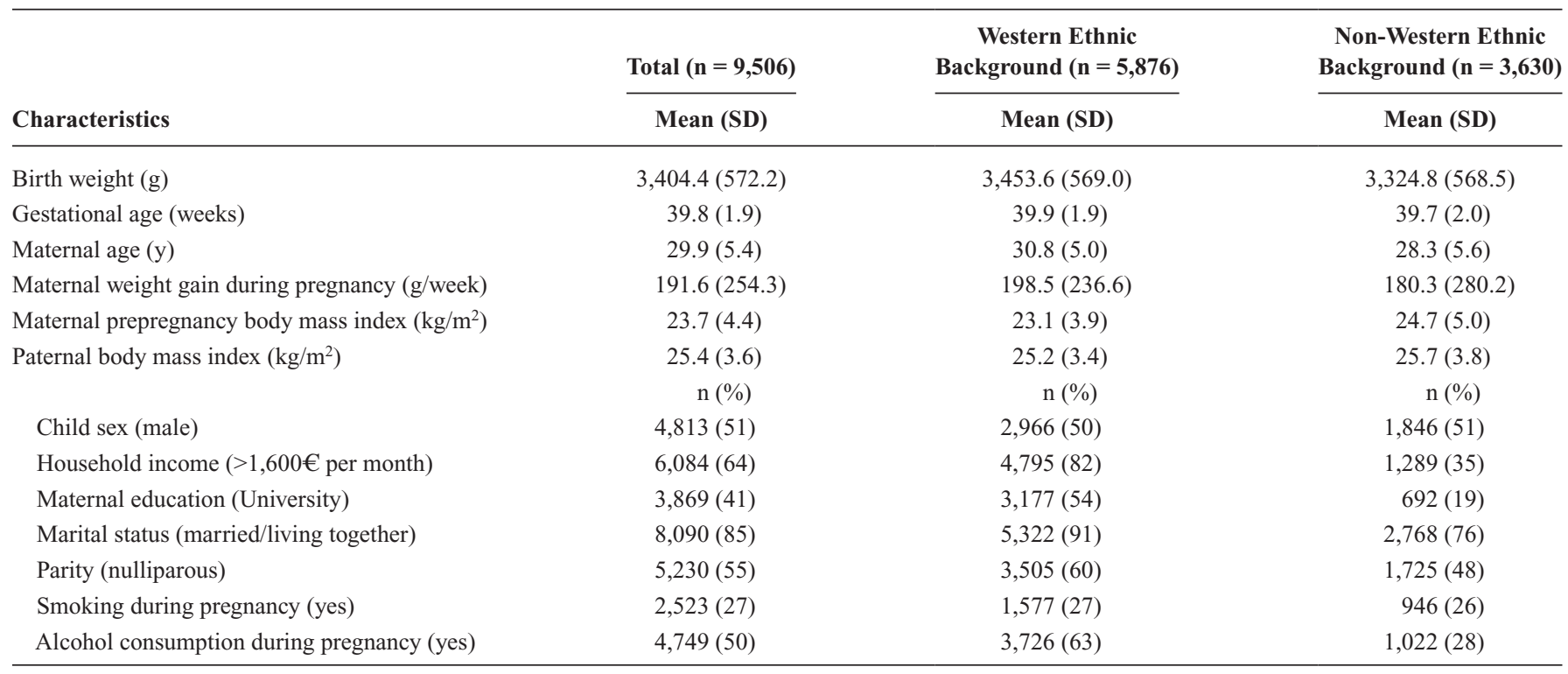

TABLE 4. Diet, Screen Time, Sports Participation, and Adiposity Measurements in Children

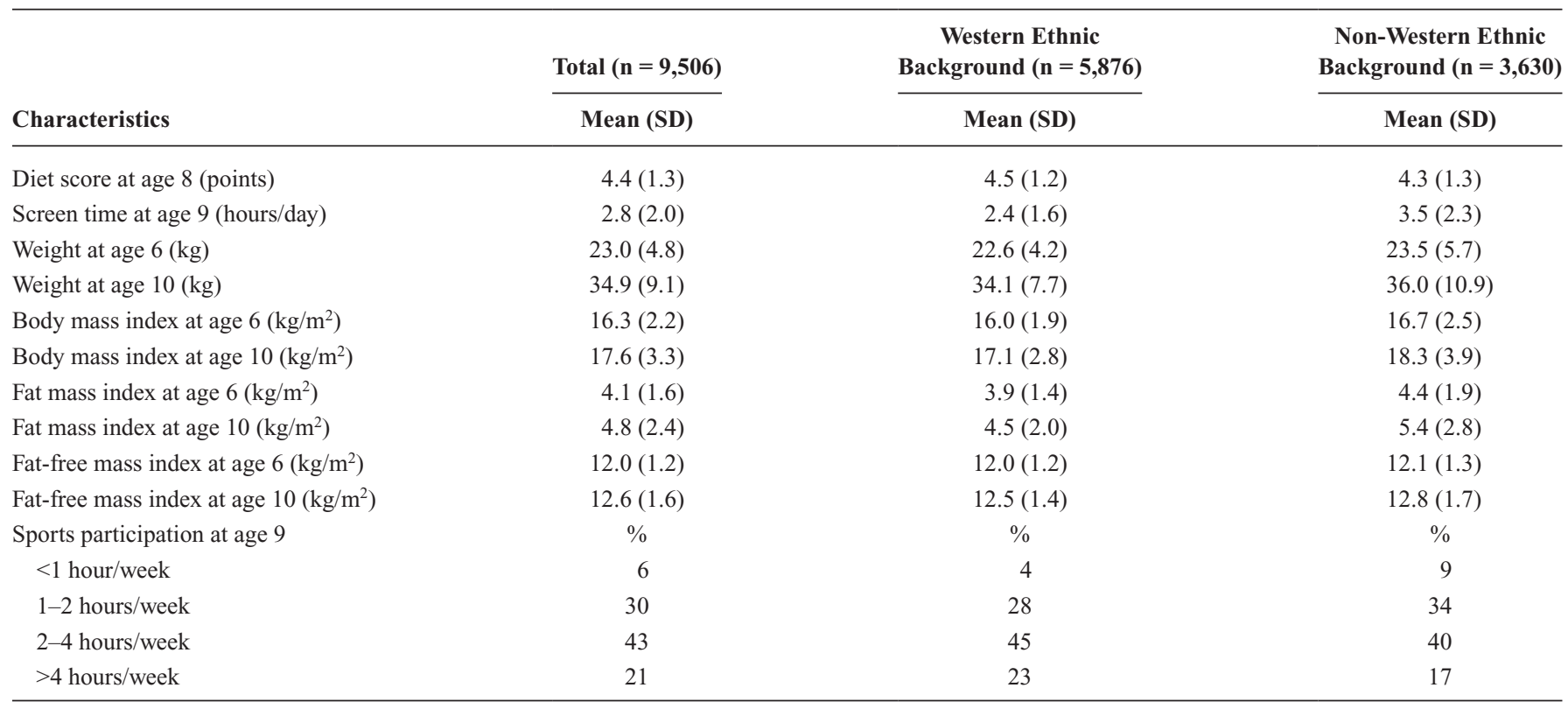

for body mass index, and $7 \%(\mathrm{CI}=4 \%, 10 \%)$ for fat mass index. The combined diet, screen time, and sports participation interventions were not associated with changes in ethnic inequalities in fat-free mass index. Similar results were found when ethnicity was dichotomized into Dutch and non-Dutch ethnic background available in eTable 2; http://links.lww. com/EDE/B679.

\section{DISCUSSION}

We estimated that implementing combined diet, screen time, and sports participation interventions was the best option to reduce ethnic inequalities in child adiposity. Although ethnic inequality reductions were larger under the ideal intervention of a maximum diet score, 0 hours screen time, and more than 4 hours a week of sports participation, the strict nature of this type of intervention would be difficult to maintain over time. ${ }^{28,29}$ The results of this study suggest that a less extreme intervention of a diet score of five points or higher, a screen time of 2 hours a day or less, and a sports participation of more than 2 hours a week reduced ethnic inequalities in weight, body mass index, and fat mass index in children at 10 years old by nearly the same amount. 
TABLE 5. Reductions in Ethnic (Western/Non-Western) Inequalities on Adiposity from Hypothetical Diet, Screen Time, and Sports Participation Interventions in Children at Age 10

\begin{tabular}{|c|c|c|c|c|}
\hline Interventions & \multicolumn{4}{|c|}{ Ethnic Inequality (1: Western, 0: Non-Western) } \\
\hline Inequality without intervention & $-1.21(-1.65,-0.77)$ & $-1.04(-1.21,-0.88)$ & $-0.79(-0.91,-0.68)$ & $-0.22(-0.29,-0.14)$ \\
\hline \multicolumn{5}{|l|}{ Diet score $=10$} \\
\hline Percentage change in inequality & $-1 \%(-3 \%, 1 \%)$ & $-1 \%(-1 \%, 0 \%)$ & $0 \%(-1 \%, 0 \%)$ & $0 \%(-2 \%, 3 \%)$ \\
\hline Percentage change in inequality & $-1 \%(-2 \%, 1 \%)$ & $0 \%(-1 \%, 0 \%)$ & $0 \%(-1 \%, 0 \%)$ & $0 \%(-2 \%, 2 \%)$ \\
\hline Inequality with intervention & $-1.20(-1.64,-0.76)$ & $-1.04(-1.21,-0.87)$ & $-0.79(-0.91,-0.68)$ & $-0.22(-0.29,-0.14)$ \\
\hline \multicolumn{5}{|l|}{ Screen time $=0$} \\
\hline Percentage change in inequality & $-16 \%(-27 \%,-5 \%)$ & $-7 \%(-11 \%,-2 \%)$ & $-7 \%(-10 \%,-3 \%)$ & $-4 \%(-13 \%, 5 \%)$ \\
\hline Inequality with intervention & $-1.02(-1.46,-0.59)$ & $-0.98(-1.15,-0.81)$ & $-0.74(-0.85,-0.63)$ & $-0.21(-0.28,-0.13)$ \\
\hline \multicolumn{5}{|l|}{ Sports participation $>4$ hours/week } \\
\hline Percentage change in inequality & $-6 \%(-10 \%,-2 \%)$ & $-3 \%(-4 \%,-1 \%)$ & $-3 \%(-4 \%,-1 \%)$ & $0 \%(-2 \%, 2 \%)$ \\
\hline Inequality with intervention & $-1.15(-1.59,-0.70)$ & $-1.02(-1.19,-0.85)$ & $-0.77(-0.89,-0.66)$ & $-0.22(-0.29,-0.14)$ \\
\hline \multicolumn{5}{|l|}{ Sports participation $>2$ hours/week } \\
\hline Percentage change in inequality & $-4 \%(-7 \%,-1 \%)$ & $-2 \%(-3 \%,-1 \%)$ & $-2 \%(-3 \%,-1 \%)$ & $0 \%(-2 \%, 2 \%)$ \\
\hline Inequality with intervention & $-1.16(-1.61,-0.72)$ & $-1.03(-1.19,-0.86)$ & $-0.78(-0.89,-0.67)$ & $-0.22(-0.29,-0.14)$ \\
\hline \multicolumn{5}{|c|}{ Combined: Diet score $=10$, screen time $=0$, and sports participation $>4$ hours $/$ week } \\
\hline Percentage change in inequality & $-21 \%(-35 \%,-8 \%)$ & $-9 \%(-14 \%,-4 \%)$ & $-9 \%(-13 \%,-6 \%)$ & $-4 \%(-13 \%, 6 \%)$ \\
\hline Inequality with intervention & $-0.96(-1.41,-0.52)$ & $-0.95(-1.12,-0.78)$ & $-0.72(-0.84,-0.61)$ & $-0.21(-0.28,-0.13)$ \\
\hline \multicolumn{5}{|c|}{ Combined: Diet score $\geq 5$, screen time $\leq 2$ hours/day, and sports participation $>2$ hours/week } \\
\hline Percentage change in inequality & $-17 \%(-28 \%,-6 \%)$ & $-7 \%(-11 \%,-3 \%)$ & $-7 \%(-10 \%,-4 \%)$ & $-3 \%(-11 \%, 5 \%)$ \\
\hline
\end{tabular}

Estimates expressed with $95 \%$ confidence intervals in parentheses.

The combined extreme intervention was able to reduce the inequality in weight by $17 \%$ and the inequality in body mass index by $8 \%$. The reason these reductions are not larger is possibly because they are applied simultaneously to both children from Western and non-Western ethnic backgrounds. The degree to which the inequality is reduced is a function of how much more the children from a non-Western ethnic background benefit from the intervention relative to those from a Western ethnic background. The reduction would have been larger if it had been only targeted toward children from a nonWestern ethnic background, but such a targeted intervention is a less realistic public health intervention than targeting all children. Also, the observed change in ethnic inequalities was over a 4 -year period (between 6 and 10 years old). It may be that longer periods of time are required to make larger gains in reducing ethnic health inequalities.

Measurement error in the intervention variables may also bias the association between the intervention and the outcome toward the null ${ }^{30}$ resulting in underestimation of the change in health inequality. Related to this is the fact that some interventions were on categorical variables. Any residual differences within a category (e.g., if children from a Western ethnic background in the highest physical activity group did more exercise than children from a non-Western ethnic background in the highest physical activity group) would not be captured in the model and thus would not contribute to the reduction in inequalities.

Screen time was associated with the highest reduction in ethnic inequalities when applied independently. This is important because screen time has increased dramatically during the last decades, ${ }^{31,32}$ and current evidence suggests that screen media exposure leads to obesity in children and adolescents mainly through increased eating while viewing, exposure to high-calorie, low-nutrient food and beverage marketing that influences children's preferences, purchase requests, and consumption habits. ${ }^{33,34}$ However, this intervention by itself is not completely well defined (i.e., does not satisfy the consistency assumption) because it depends on what a child will do with the time they would normally have been in front of a screen. The more specific the intervention the easier it is to generalize 
results and guide the elaboration and evaluation of public health interventions. In this study, combined interventions partially address this issue by specifying that while the child is reducing screen time they are also increasing sport participation and improving diet quality.

Currently, comprehensive evidence is lacking on what works in terms of interventions to reduce inequalities in childhood obesity. ${ }^{35-37}$ A systematic review that examined the best available international evidence from interventions to reduce socioeconomic inequalities in obesity-related outcomes among children found that individual-level, screen time reduction, and mentor-based health promotion interventions could be effective in reducing inequalities in childhood obesity because they were more beneficial for low socioeconomic children who already had obesity. For community- and societal-level interventions, the evidence was inconclusive. ${ }^{38}$

Although body mass index is the most common measure of obesity at the population level it fails to distinguish between fat and fat-free mass and may exaggerate obesity in large muscular children. ${ }^{3}$ For this reason, we also included measurements such as fat mass index and fat-free mass index to have more complete information about the child's body composition. We observed that with the hypothetical interventions all measurements related with child adiposity had the same direction of effect, they consistently decreased in both ethnic groups. When looking at relative reductions, we observed that the decrease was higher in the group of children with a non-Western ethnic background than with a Western ethnic background, which translated into a reduction of the ethnic inequality. With respect to fat-free mass index, the change in ethnic inequality with the hypothetical interventions did not change much from the ethnic inequality without the interventions. This suggest that the hypothetical interventions were more associated with reducing measures of adiposity than fatfree mass.

In this study, there were differences by ethnicity in all adiposity measurement among children at birth, 6 years old, and 10 years old, and these differences increased over time, with less healthy levels for children from non-Western than Western ethnic backgrounds. A European systematic review of the literature concluded that children of migrants were more at risk of overweight and obesity than native children. ${ }^{4}$ Previous studies conducted in the Netherlands found that prevalence of overweight and obesity was especially alarming among children in the two residing largest migrant groups: those from Turkish and Moroccan descent. . $^{39,40}$

There were also differences in diet, screen time, and sports participation by ethnicity, and children from a nonWestern ethnic background had less healthy behaviors. It has been described that migrants tend to abandon their traditional food habits, adopt westernized dietary patterns, and engage in a more sedentary way of life. ${ }^{41,42}$

Alterations in physical activity, leading to a more sedentary way of life, have been reported in immigrants compared with women and men born in Sweden. ${ }^{43}$ Also, migrant children in European countries displayed lower levels of physical activity than native ones. ${ }^{4,44,45} \mathrm{~A}$ systematic review about physical activity among North African immigrant children in European countries found that one of the major predisposing factors to obesity is the lack of a health-conscious exercise culture. ${ }^{46}$ Another aspect responsible for sedentary lifestyle during childhood is the high exposure to media, in particular television, which exposes children to advertising for highenergy snacks and reduces physical activity. ${ }^{41}$ The evidence suggests that daily screen time for more than 2 hours is associated with unfavorable body composition and that lowering sedentary time leads to reductions in body mass index and health risk both in children and youth. ${ }^{47}$

With respect to dietary habits, a systematic review showed that some ethnic groups in Europe are likely to become less healthy as individuals increase consumption of processed foods that are energy dense and contain high levels of fat, sugar, and salt. After migration, the majority of ethnic groups observed alter their eating habits, combining parts of their traditional diet with some of the less healthy elements of the Western diet, such as soft drinks, sweets, and snacks that are higher in fat or sugar and lower in dietary fiber than the legumes and grains of the traditional diet. These mixed food habits are emerging mainly among younger people, probably as the consequence of acculturation processes, which increases the risk of overweight and obesity. ${ }^{41}$

Ethnic inequalities in child adiposity might be explained at individual level by the lack of exercise, increasing consumption of less healthy foods, genetic predisposition, and stress related to migration and settlement of the family. Additionally, acculturation and stronger integration within the new host country have been associated with a decline in the health of immigrants. ${ }^{41,46}$ Other factors are income, food availability, religion, food beliefs, body size preferences, age, immigrant generation, and country of origin. ${ }^{41,48-51}$ Therefore, effective public health interventions aimed to reduce ethnic inequalities in child adiposity need to be culturally sensitive and these only can be adequately designed, if particular lifestyle behaviors that influence the elevated risk among specific ethnic groups are identified. ${ }^{48}$

This is one of the first studies using this methodology to quantify the reductions in ethnic inequalities in child adiposity at 10 years old from hypothetical diet, screen time, and sports participation interventions. There have been important advances in methodology in the study of health inequalities in the context of causal inference recently ${ }^{23,24}$ that have helped researchers target the parameter of interest: how interventions decrease inequalities. Whereas many studies adjust the ethnic inequality for confounders of the ethnicity-outcome relationship,,$^{24,25}$ this study employs special methods to avoid this. The rationale is that health inequalities are of interest unadjusted for other variables because the interest is in real-world differences in health variables by ethnicity, not the difference after 
adjusting for confounders. Therefore, in analyses that estimate the reduction in a health inequality due to a specific intervention, the interest is in the reduction in health disparity unadjusted for covariates. By employing these methods, the results of this research help to better understand how interventions could reduce ethnic inequalities in children and to be realistic about what effect size to expect. Other strengths include that the results obtained came from a population-based, multicultural cohort study and that multiple imputation was performed to avoid potential selection bias and to have representative information.

Among the limitations of this study is that information recall and social desirability bias could affect the food frequency and screen time questionnaires. ${ }^{52,53}$ Recall bias may occur because the food frequency questionnaire required participants to remember their diet during the last 4 weeks, which cannot be done with perfect accuracy, and the social desirability bias refers to the tendency to give response that are viewed more favorably by the interviewer. Another potential limitation is the cross-cultural validity of the diet score, because for religious or other beliefs, specific ethnic groups may avoid certain foods that are considered healthier and this could make one group's diet score appear better than another group's. ${ }^{54}$ Also, the presence of differential missing data by ethnicity may lead to an underestimation of the ethnic inequalities in child adiposity. We used multiple imputation to ensure that all participants were included in the analysis to avoid this bias. Nonetheless, the results could still be biased to the degree that missingness is related to variables not used in the imputation. We attempted to minimize this by including all variables from the analyses in the imputation and additional variables found to be related to missingness. Last, unmeasured confounding of the intervention-outcome model would lead to an overestimate of the change in ethnic inequalities in child adiposity.

This study generates evidence that could help, in conjunction with other research, to guide public health interventions to reduce ethnic inequalities in child health. For future research, it would be interesting to use this methodology to evaluate the effect of public health interventions on cardiometabolic risk. Also, longitudinal models could be developed to follow participants over time to identify the age at which interventions to reduce ethnic inequalities are most effective.

\section{ACKNOWLEDGMENTS}

The Generation R Study is conducted by Erasmus Medical Center in close collaboration with the School of Law and Faculty of Social Sciences of the Erasmus University Rotterdam; the Municipal Health Service Rotterdam area, Rotterdam; the Rotterdam Homecare Foundation, Rotterdam; and the Stichting Trombosedienst \& Artsenlaboratorium Rijnmond (STAR-MDC), Rotterdam. We gratefully acknowledge the contribution of children and parents, general practitioners, hospitals, midwives, and pharmacies in Rotterdam. The general design of Generation $R$ Study is made possible by financial support from the Erasmus Medical Center, Rotterdam, the Erasmus University Rotterdam, the Netherlands Organization for Health Research and Development (ZonMw), the Netherlands Organisation for Scientific Research (NWO), the Ministry of Health, Welfare and Sport, and the Ministry of Youth and Families.

\section{REFERENCES}

1. World Health Organization. Obesity and overweight. Geneva. 2018 Available at: http://www.who.int/mediacentre/factsheets/fs311/en/. Accessed 20 February 2020.

2. NCD Risk Factor Collaboration. Worldwide trends in body-mass index underweight, overweight, and obesity from 1975 to 2016: a pooled analysis of 2416 population-based measurement studies in 128.9 million children, adolescents, and adults. Lancet. 2017;390:2627-2642.

3. Verrotti A, Penta L, Zenzeri L, Agostinelli S, De Feo P. Childhood obesity: prevention and strategies of intervention. A systematic review of school-based interventions in primary schools. $J$ Endocrinol Invest. 2014;37:1155-1164

4. Labree LJ, van de Mheen H, Rutten FF, Foets M. Differences in overweight and obesity among children from migrant and native origin: a systematic review of the European literature. Obes Rev. 2011;12:e535-e547.

5. El-Sayed AM, Scarborough P, Galea S. Ethnic inequalities in obesity among children and adults in the UK: a systematic review of the literature. Obes Rev. 2011;12:e516-e534.

6. de Wilde JA, Meeuwsen RC, Middelkoop BJ. Growing ethnic disparities in prevalence of overweight and obesity in children 2-15 years in the Netherlands. Eur J Public Health. 2018;28:1023-1028.

7. Ersanilli EF. Country profile 11: the Netherlands. Focus Migration Information Service. 2007. Available at: http://focus-migration.hwwi.de/ uploads/tx_wilpubdb/CP11_Netherlands.pdf. Accessed 12 March 2020.

8. Statistics Netherlands (CBS). Bevolking; generatie, geslacht, leeftijd en migratieachtergrond, 1 januari. The Hague/Heerlen. 2019 Available at: https://opendata.cbs.nl/statline/\#/CBS/nl/dataset/37325/ table?fromstatweb. Accessed 12 March 2020

9. European Portal for Action on Health Inequalities. Health Inequalities in The Netherlands. 2017. Available at: http://www.health-inequalities. eu/about-hi/at-national-level/the-netherlands/. Accessed 12 December 2019.

10. National Institute for Public Health and the Environment (RIVM). Dutch Public Health Foresight Report (VTV): Health inequalities. 2018. Available at: https://www.vtv2018.nl/en/health-inequalities. Accessed 18 January 2020.

11. Perini W, Snijder MB, Peters RJG, Kunst AE. Ethnic disparities in estimated cardiovascular disease risk in Amsterdam, the Netherlands: The HELIUS study. Neth Heart J. 2018;26:252-262.

12. Ujcic-Voortman JK, Baan CA, Seidell JC, Verhoeff AP. Obesity and cardiovascular disease risk among Turkish and Moroccan migrant groups in Europe: a systematic review. Obes Rev. 2012;13:2-16.

13. Gishti O, Gaillard R, Felix JF, et al. Early origins of ethnic disparities in cardiovascular risk factors. Prev Med. 2015;76:84-91.

14. Umer A, Kelley GA, Cottrell LE, Giacobbi P Jr, Innes KE, Lilly CL. Childhood obesity and adult cardiovascular disease risk factors: a systematic review with meta-analysis. BMC Public Health. 2017;17:683.

15. Kooijman MN, Kruithof CJ, van Duijn CM, et al. The Generation R Study: design and cohort update 2017. Eur J Epidemiol. 2016;31:1243-1264.

16. Entzinger H, Engbersen G. Rotterdam: A Long-Time Port of Call and Home to Immigrants. Washington, DC: Migration Policy Institute; 2014. Available at: https:/www.migrationpolicy.org/sites/default/files/publications/TCM_Cities_Rotterdam.pdf. Accessed 16 March 2020.

17. Statistics Netherlands (CBS). Bevolking op 1 januari; leeftijd, geboorteland en regio. 2019. Available at: https://opendata.cbs.nl/statline/\#/CBS $\mathrm{nl} /$ dataset/70648ned/table?ts=1542207348734. Accessed 14 March 2020

18. Statistics Netherlands (CBS). Classification of the Population with a foreign background in the Netherlands. 2001. Available at: https://www 
cbs.nl/-/media/imported/documents/2002/05/classification-foreign pdf?la=nl-nl. Accessed 16 March 2020.

19. Netherlands Nutrition Centre. [The Wheel of Five - Dutch Dietary Guidelines]. 2016. Available at: https://www.voedingscentrum.nl/Assets Uploads/voedingscentrum/Documents/Professionals/Schijf\%20van\%20 Vijf/Richtlijnen\%20Schijf\%20van\%20Vijf.pdf. Accessed 17 March 2020.

20. van der Velde LA, Nguyen AN, Schoufour JD, et al. Diet quality in childhood: the Generation R Study. Eur J Nutr. 2019;58:1259-1269.

21. Wijtzes AI, Bouthoorn SH, Jansen W, et al. Sedentary behaviors, physical activity behaviors, and body fat in 6-year-old children: the generation $\mathrm{R}$ study. Int J Behav Nutr Phys Act. 2014;11:96.

22. Valeri L, Vanderweele TJ. Mediation analysis allowing for exposuremediator interactions and causal interpretation: theoretical assumptions and implementation with SAS and SPSS macros. Psychol Methods. 2013; 18:137-150.

23. VanderWeele TJ, Robinson WR. On the causal interpretation of race in regressions adjusting for confounding and mediating variables. Epidemiology. 2014;25:473-84.

24. Jackson JW, VanderWeele TJ. Decomposition analysis to identify intervention targets for reducing disparities. Epidemiology. 2018;29:825-835

25 . Vansteelandt S. Estimating direct effects in cohort and case-control studies. Epidemiology. 2009;20:851-860.

26. Hernán MA, Hernández-Díaz S, Robins JM. A structural approach to selection bias. Epidemiology. 2004;15:615-625.

27. van Buuren S, Groothuis-Oudshoorn CG. Mice: multivariate imputation by chained equations in R. J Stat Softw. 2011;45:1-67.

28. Kwasnicka D, Dombrowski SU, White M, Sniehotta F. Theoretical explanations for maintenance of behaviour change: a systematic review of behaviour theories. Health Psychol Rev. 2016;10:277-296.

29. Teixeira PJ, Carraça EV, Marques MM, et al. Successful behavior change in obesity interventions in adults: a systematic review of self-regulation mediators. BMC Med. 2015;13:84.

30. Hutcheon JA, Chiolero A, Hanley JA. Random measurement error and regression dilution bias. $B M J .2010 ; 340: \mathrm{c} 2289$.

31. Bucksch J, Sigmundova D, Hamrik Z, et al. International trends in adolescent screen-time behaviors from 2002 to 2010. J Adolesc Health. 2016;58:417-425.

32. Saunders TJ, Chaput JP, Tremblay MS. Sedentary behaviour as an emerging risk factor for cardiometabolic diseases in children and youth. Can $J$ Diabetes. 2014;38:53-61.

33. Robinson TN, Banda JA, Hale L, et al. Screen media exposure and obesity in children and adolescents. Pediatrics. 2017;140(Suppl 2):S97-S101.

34. Börnhorst C, Wijnhoven TM, Kunešová M, et al. WHO European childhood obesity surveillance initiative: associations between sleep duration, screen time and food consumption frequencies. BMC Public Health. 2015; 15:442.

35. Bambra CL, Hillier FC, Cairns JM, Kasim A, Moore HJ, Summerbell CD. How effective are interventions at reducing socioeconomic inequalities in obesity among children and adults? Two systematic reviews. Public Health Research. 2015;3.

36. Waters E, de Silva-Sanigorski A, Hall BJ, et al. Interventions for preventing obesity in children. Cochrane Database Syst Rev. 2011:CD001871.

37. Magnée T, Burdorf A, Brug J, et al. Equity-specific effects of 26 Dutch obesity-related lifestyle interventions. Am J Prev Med. 2013;44:e57-e66.
38. Hillier-Brown FC, Bambra CL, Cairns JM, Kasim A, Moore HJ, Summerbell CD. A systematic review of the effectiveness of individual, community and societal level interventions at reducing socioeconomic inequalities in obesity amongst children. BMC Public Health. 2014;14:834.

39. de Wilde JA, van Dommelen P, Middelkoop BJ, Verkerk PH. Trends in overweight and obesity prevalence in Dutch, Turkish, Moroccan and Surinamese South Asian children in the Netherlands. Arch Dis Child. 2009;94:795-800.

40. Fredriks AM, Van Buuren S, Sing RA, Wit JM, Verloove-Vanhorick SP. Alarming prevalences of overweight and obesity for children of Turkish, Moroccan and Dutch origin in The Netherlands according to international standards. Acta Paediatr. 2005;94:496-498.

41. Gilbert PA, Khokhar S. Changing dietary habits of ethnic groups in Europe and implications for health. Nutr Rev. 2008;66:203-215.

42. Rovillé-Sausse FN. Westernization of the nutritional pattern of Chinese children living in France. Public Health. 2005;119:726-733.

43. Dawson AJ, Sundquist J, Johansson SE. The influence of ethnicity and length of time since immigration on physical activity. Ethn Health. 2005; 10:293-309.

44. Eyre EL, Duncan MJ, Smith EC, Matyka KA. Objectively measured patterns of physical activity in primary school children in Coventry: the influence of ethnicity. Diabet Med. 2013;30:939-945.

45. Owen CG, Nightingale CM, Rudnicka AR, Cook DG, Ekelund U, Whincup PH. Ethnic and gender differences in physical activity levels among 9-10-year-old children of white European, South Asian and African-Caribbean origin: the Child Heart Health Study in England (CHASE Study). Int J Epidemiol. 2009;38:1082-1093.

46. Gualdi-Russo E, Zaccagni L, Manzon VS, Masotti S, Rinaldo N, Khyatti M. Obesity and physical activity in children of immigrants. Eur J Public Health. 2014;24(Suppl 1):40-46.

47. Tremblay MS, LeBlanc AG, Kho ME, et al. Systematic review of sedentary behaviour and health indicators in school-aged children and youth. Int J Behav Nutr Phys Act. 2011;8:98.

48. Nicolaou M, Doak CM, van Dam RM, Brug J, Stronks K, Seidell JC. Cultural and social influences on food consumption in Dutch residents of Turkish and moroccan origin: a qualitative study. J Nutr Educ Behav. 2009;41:232-241.

49. Al-Sendi AM, Shetty P, Musaiger AO. Body weight perception among Bahraini adolescents. Child Care Health Dev. 2004;30:369-376.

50. Becker AE, Gilman SE, Burwell RA. Changes in prevalence of overweight and in body image among Fijian women between 1989 and 1998. Obes Res. 2005;13:110-117.

51. Mokhtar N, Elati J, Chabir R, et al. Diet culture and obesity in northern Africa. J Nutr. 2001;131:887S-892S.

52. Olafsdottir AS, Thorsdottir I, Gunnarsdottir I, Thorgeirsdottir H, Steingrimsdottir L. Comparison of women's diet assessed by FFQs and 24-hour recalls with and without underreporters: associations with biomarkers. Ann Nutr Metab. 2006;50:450-460.

53. Westerterp KR, Goris AH. Validity of the assessment of dietary intake: problems of misreporting. Curr Opin Clin Nutr Metab Care. 2002;5:489-493.

54. Labree W, van de Mheen D, Rutten F, Rodenburg G, Koopmans G, Foets M. Differences in overweight and obesity among children from migrant and native origin: the role of physical activity, dietary intake, and sleep duration. PLoS One. 2015;10:e123672. 